\title{
THE EFFECT OF AGRICULTURAL FUTURES PRICE CHANGES ON THE AGRICULTURAL PRODUCTION IN AP VOJVODINA
}

\author{
Dejan Živkov ${ }^{1}$, Nataša Papić-Blagojević ${ }^{2}$, Sanja Lončar ${ }^{3}$ \\ *Corresponding authorE-mail: dejanzivkov@gmail.com
}

\begin{abstract}
A R T I C LE IN F O
A B S T R A C T

Original Article

Received: 29 August 2019

Accepted: 16 September 2019

doi:10.5937/ekoPolj1903755Z

UDC 338.57:631.5(497.113)

Keywords:

Agricultural futures, Bayesian quantile regression estimation

This paper investigates whether global agricultural futures of corn, wheat, oats, soybean and canola have any influence on the annual agricultural production of these plants in AP Vojvodina. For the estimation purposes, the study applies robust Bayesian quantile regression. Besides, two scenarios are considered - 1) current futures prices, and 2) futures prices from the previous year. Estimated results suggest that current futures prices do not affect current agricultural production of corn, wheat, oats and soybean in AP Vojvodina, because the estimated quantile parameters have negative sign or they are very small. However, when JEL: C11, Q14 futures prices from the previous year are analysed, the majority of estimated QR parameters bear positive sign, which means that Serbian farmers take into account in greater or lesser extent the global agricultural prices when they plan their annual agricultural plantation. According to the findings, canola futures have the greatest effect on the rising Serbian canola production.
\end{abstract}

(C) 2019 EA. All rights reserved.

\section{Introduction}

It is well known among market practitioners and scholars that agricultural commodity prices have been characterized by a huge rise in volatility in recent two decades. According to Gilbert (2010) and $\mathrm{Li}$ and $\mathrm{Lu}$ (2012), a number of reasons has been listed as possible culprits: the rapid economic growth of China and India, the biofuel programs of the US and the European Union, speculative trading activities, changing climate conditions, significant variation in harvests and inventory levels of agricultural

1 Dejan Živkov, Lecturer at Novi Sad business school, University of Novi Sad, Address: Vladimira Perića Valtera 4, 21000 Novi Sad, Serbia, email: dejanzivkov@gmail.com, ORCID ID https://orcid.org/0000-0003-2357-3250

2 Nataša Papić-Blagojević, Professor at Novi Sad business school, University of Novi Sad, Address: Vladimira Perića Valtera 4, 21000 Novi Sad, Serbia, email: npapic.blagojevic@ gmail.com, ORCID ID https://orcid.org/0000-0002-1110-3414

3 Sanja Lončar, Professor at Novi Sad business school, University of Novi Sad, Address: Vladimira Perića Valtera 4, 21000 Novi Sad, Serbia, email: Sanja.Loncar@vps.ns.ac.rs, ORCID ID https://orcid.org/0000-0003-3904-6826 
products, and so forth. Due to these uncertainties, global agricultural producers have difficulties to plan their annual production levels of a particular crop as well as their overall agricultural investments. In order to protect themselves from the global agricultural price changes, futures stand as a suitable mean for the risk reduction, which helps global farmers to efficiently hedge against risk of agricultural price changes (see Birovljev et al., 2012; Kuzman et al., 2018).

Gulan (2014) contended that production of agricultural sector in Serbia vis-à-vis Serbian GDP is relatively significant, and it ranged between $11.8 \%-15.5 \%$ in the period 20022012. From that amount, participation of plant production was $67.8 \%$, while livestock amounted 30.0\% in 2013. In addition, Đurić et al. (2017) asserted that agricultural and food sector has an important role in the economic development of Republic of Serbia, whereas it significantly participates in the structure of domestic exports. Therefore, one of the basic interests of Serbian farmers is to know at what price they can sell their agricultural products after they finish harvest. This factor also plays a major role in the process of decisioning how many hectares of which agricultural crop will be planted.

Having in mind aforementioned, this paper investigates whether and in which extent global agricultural futures prices affect annual agricultural production in Serbia. The following agricultural commodities are selected - corn, wheat, soybean, oats and canola. Futures prices are considered rather than spot prices, because futures incorporate all available information known up to present time, but also cover predictions and expectations about incoming events (see Natanelov et al., 2011). In the process of decision making how many hectares will be covered by particular crop, farmers usually take into account the agricultural prices from the previous year. Therefore, the primary research of this paper tries to stipulate how futures prices from the previous year affect the current agricultural production in Serbia. In addition, a less likely scenario is also considered, which involves estimation of how current futures prices impact current agricultural production. These results serve for the comparison purposes. We hypothesize that agricultural futures prices have an effect on the agricultural production in Serbia, but the extent of this effect on the production heavily differentiates between the selected commodities.

In addition, we want to see whether the connection between global futures prices and Serbian agricultural production depends on different level of Serbian annual agricultural production. In other words, the goal is to see whether high futures prices instigate increased agricultural production, and vice-versa. This type of estimation is feasible if the influence of futures prices, as independent variable, is observed on different quantiles of agricultural production, as independent variable. Therefore, in order to conduct this type of research, the paper utilizes robust Bayesian quantile regression (QR), which uses MCMC (Markov Chain Monte Carlo) algorithm in the estimation process. Bayesian QR is useful because it produces exact inference about the quantile parameters, i.e. all Bayesian quantile parameters are statistically significant. More precisely, Bayesian QR methodology in comparison with the traditional QR of Koenker and Bassett (1978) decreases the length of the credible intervals, and increases accurateness of the quantile estimates. 
This paper adds to the literature by investigating thoroughly the impact of agricultural futures prices on the agricultural production in Serbia, by using elaborate Bayesian QR methodology. To the best of our knowledge, this paper is the first one in the extant literature, which did this type of research. The significance of the paper could be in answering whether farmers in Serbia consider financial derivatives when they plan agricultural plantation. Also, this paper could rise an awareness of practical usefulness of agricultural futures in the process of price changes risk reduction, which poses a major problem in Serbia for many years.

Besides introduction, the rest of the paper is structured as follows. Second section gives a brief literature review. Third section explains used methodology. Forth section presents dataset and their statistical properties. Fifth section is reserved for the results, while the last section concludes.

\section{Brief literature review}

Generally speaking, futures have become one of the most important financial instruments in last few decades for information processing, price discovery, hedging and various diversification strategies. This subject of research is important for farmers in Serbia since agricultural market in Serbia is disorganized, according to Ignjatijević et al. (2018). They asserted that agricultural market in Serbia has the characteristics of a perfectly competitive market regarding supply, and the characteristics of the oligopoly regarding demand. Also, they argued that there is no cooperation between the producers and processors. Besides, Haile et al. (2017) contended that weather extremes, such as shocks in both temperature and precipitation during crop growing months have serious consequences on the production and supply of agricultural commodities, which strongly influences their prices. Marković et al. (2013) added that Government should determine minimum price of agricultural products in advance in order producers know the level of profit they can count with. However, if this type of mechanism is unavailable, some other form of price change protection would be of great help for farmers in Serbia.

Accordingly, this section concisely presents the studies that deals with the topic of agricultural futures regarding different perspectives. For instance, Dimpfl et al. (2017) consider price discovery of spot and futures markets for six major seasonal and nonseasonal agricultural commodities. They drew a conclusion that efficient price of agricultural commodities is determined on the spot market in the long-run. Bohl et al. (2018) empirically researched whether speculative activities in Chinese agricultural futures markets destabilizes futures returns. They found evidence of a positive influence of the speculation ratio on conditional volatility. Bohl et al. (2019) investigated how speculation affects the price discovery function of four agricultural commodity futures markets. They revealed that speculation, both total and excessive, improves futures markets' price discovery function. They asserted that speculation reduces the level of noise incorporated in the futures prices and it increases the speed at which the futures prices reflect new information about changes in market fundamentals. 
Beckmann and Czudaj (2014) investigated the volatility spillover between various agricultural futures markets - corn, cotton, and wheat. They used GARCH-in-mean VAR models and provided evidence that short-run volatility transmission process exists in the agricultural futures markets. Jia et al (2016) studied the dynamic lead-lag relationship between the Chinese and American agricultural futures markets in both returns and volatility. They considered soybean, corn and wheat. They disclosed that the volatility transmission from the US to China wheat futures market takes longer time than soybean. They concluded that reason probably lies in a fact that China's soybean futures market is more closely linked to the international agricultural futures market than wheat. Ma et al. (in press) explored the effect of co-jumps within the agricultural futures market, and co-jumps between the agricultural futures market and the stock market, on stock volatility forecasting. They found that large jumps may lead to more substantial fluctuations and are more powerful than small jumps. They contended that a model, which includes large and small co-jumps between the agricultural futures market and the stock market can achieve a higher forecasting accuracy.

\section{Bayesian quantile regression methodology}

Traditional quantile regression technique was developed by Koenker and Bassett (1978). This particular methodology extends the mean regression model to conditional quantiles of the response variable. Utilizing this approach, researchers can gain more detailed view of the relationship between response variable and covariates, because it allows researchers to estimate how a set of covariates influence the different parts of the distribution of the dependent variable. This characteristic of QR methodology have been found appealing by many researchers from various theoretical disciplines (see e.g. Maestri, 2013; and Živkov et al., 2014). Also, Benoit and van den Poel (2012) contended that parameter estimates of QR are not biased by a location-scale shift of the conditional distribution of dependent variable.

The goal of this paper is to determine how futures price changes affect the changes in the agricultural production in AP Vojvodina. As have been said previously, the interdependence is observed in two ways: 1) when the current futures price changes affect the current production (equation 1), and 2) when the previous year futures price changes impact the current production (equation 2 ).

$$
\begin{gathered}
A P C_{i, t}=F P C_{i, t}+\varepsilon_{i, t} \\
A P C_{i, t}=F P C_{i, t-1}+\bar{\varepsilon}_{i, t}
\end{gathered}
$$

where $A P C_{i, t}$ denotes agricultural production changes of a particular crop $(i)$ at the time $(t), F P C_{i, t}$ and $F P C_{i, t-1}$ stand for futures price changes of particular crop $(i)$ at the times $(t)$ and $(t-1)$, while $\varepsilon$ and $\bar{\varepsilon}$ are white noise error terms in both equations. 
Benoit and van den Poel (2017) explained that if $\operatorname{Med}(\varepsilon \mid x)=0$ is assumed, then $\mu\left(x_{i}\right)$ is a conditional median function, while a linear conditional median model is given by $\operatorname{Med}\left(y_{i} \mid x_{i}\right)=x_{i}^{\prime} \beta$. Accordingly, the regression parameter can be found by solving equation (3):

$$
\operatorname{argmin} \sum_{i=1}^{\mathrm{n}}\left|\mathrm{y}_{\mathrm{i}}-\mathrm{x}_{1}^{\prime} \beta\right| ; \quad \beta \in \Re
$$

Quantile regression extends the median case to all other quantiles, and these quantile parameters can be estimated by solving the equation (4):

$$
\hat{\beta}(\tau)=\operatorname{argmin} \sum_{i=1}^{n} \rho_{\tau}\left(y_{i}-x_{1}^{\prime} \beta\right) ; \quad \beta \in \Re
$$

where $\tau \in(0,1)$ is any quantile of interest, while $\rho_{\tau}(z)=z(\tau-I(z<0))$ and $I(\cdot)$ stands for the indicator function. The quantile $\hat{\beta}(\tau)$ is called the $\tau^{\text {th }}$ regression quantile, while in the case where $\tau=0.5$, it corresponds to median regression.

According to Benoit and van den Poel (2017), first step in the implementation of the Bayesian quantile regression ${ }^{4}$ involves the formation of a likelihood comprised of independent asymmetric Laplace densities with $\mu=x_{\imath}^{\prime} \beta$, specifying the quantile of interest ( $\mathrm{t}$ ). The model parameters are then estimated by conventional Bayesian procedure, which uses MCMC algorithm, producing the exact inference about $\hat{\beta}(\tau)$ Sriram et al. (2012) asserted that key advantage of the Bayesian quantile regression comparing to the conventional QR model is the fact that $95 \%$ Bayesian credible interval contains the true parameter value $95 \%$ of the time. These authors explained that with increasing sample size, coverage improves, while the length of the credible intervals decreases.

\section{Dataset and statistical properties of the selected time-series}

This paper uses annual data of five cereals - corn, wheat, soybean, oats and canola. In particular, we observe futures prices of these agricultural commodities and the annual production in tons in Serbia, observing only the production in the area of Autonomous province of Vojvodina. Our data sample covers the period from 2005-2018, and the reason why longer time-span is not observed lies in the fact that the futures prices for canola exist only from 2005. Futures prices are collected from Chicago mercantile exchange (CME), whereas the data for agricultural production is taken from the official website of Statistical office of the Republic of Serbia. This analysis is limited to these five cereals, because only these agricultural commodities are traded in CME, and they are also produced in Serbia. Due to the fact that our data-sample comprises relatively low number of observations, this paper uses Bayesian quantile regression,

4 Bayesian quantile parameters were calculated via 'bayesQR' package in 'R' software. 
rather than traditional QR. This is because Bayesian QR is robust methodology, capable of producing efficient quantile estimates even in low data environment, which traditional QR cannot do. This paper does not embed the raw empirical data in Equation (1) and (2), but all data are transformed in rates of return, according to the expression:

$r_{i, t}=\ln \left(P_{i, t} / P_{i, t-1}\right) \times 100$.

Table 1 provides descriptive statistics of the agricultural production changes and agricultural futures price changes, while Figures 1 and 2 present graphically their dynamics. Figures 1 and 2 clearly show erratic dynamics of futures prices and annual production in the observed period, thus it is justifiable to check is there any connection between the global futures prices and the agricultural production in AP Vojvodina.

Table 1. Descriptive statistics of agricultural production changes and futures price changes

\begin{tabular}{|l|c|c|c|c|c|c|c|}
\hline & $\begin{array}{c}\text { Mean in } \\
\%\end{array}$ & Minimum & Maximum & St. dev. & Skewness & Kurtosis & JB \\
\hline Panel A: Annual agricultural production changes \\
\hline Corn & 0.485 & 55.990 & -65.768 & 42.453 & -0.214 & 1.733 & 0.969 \\
\hline Wheat & 1.823 & 28.325 & -27.550 & 17.796 & -0.132 & 2.075 & 0.501 \\
\hline Oats & -1.874 & 30.131 & -35.676 & 18.891 & 0.000 & 2.206 & 0.342 \\
\hline Soybean & 4.244 & 44.679 & -45.964 & 29.757 & -0.256 & 1.695 & 1.065 \\
\hline Canola & 28.748 & 139.801 & -86.325 & 63.422 & -0.117 & 2.519 & 0.155 \\
\hline Panel B: Annual futures price changes & \multicolumn{7}{|l}{} \\
\hline Corn & 4.252 & 59.267 & -50.357 & 26.104 & 0.241 & 3.918 & 0.583 \\
\hline Wheat & 3.030 & 56.898 & -37.090 & 28.793 & 0.463 & 2.070 & 0.933 \\
\hline Oats & 2.651 & 35.233 & -37.893 & 23.979 & -0.366 & 2.026 & 0.804 \\
\hline Soybean & 3.042 & 56.202 & -23.154 & 22.714 & 0.917 & 3.254 & 1.857 \\
\hline Canola & 5.543 & 48.038 & -31.338 & 22.277 & 0.355 & 2.568 & 0.375 \\
\hline
\end{tabular}

Note: JB stands for Jarque-Bera test of normality.

Source: Authors' calculation.

Taking into account all the selected agricultural commodities, it can be seen in Figure 2 that largest annual production in AP Vojvodina goes to corn, while wheat and soybean follow. Also, it is interesting to note that canola is the only plant which records steady increase in production since 2014. One of the reasons of the increased canola production could be the fact that canola is used in bio-diesel production. According to Mahbub et al. (2019), bioenergy made up to $14 \%$ of the total renewable sources of energy production in 2016, while its future production is projected to constitute up to $35 \%$ of global energy by 2050. This author contends that among the liquid transportation biofuels, ethanol and biodiesel are the two most widely produced for the global market. Therefore, it is highly likely that Serbian farmers increase canola production because of the growing global demand and steady selling price of this agricultural commodity. Increased canola production in recent years is the main reason why Table 1 reports high yearly production changes in Panel A. In accordance with that, minimum, maximum and standard deviation values are also most pronounced for canola. Corn production 
changes also have relatively high standard deviation, which imply relatively high changes in annual production. The reason could be the fact that corn production heavily depends on the number of rainy days in June, July and August, and due to frequent droughts, corn production oscillates considerably. All skewness and kurtosis values are relatively low, which means that all annual agricultural production changes follow Gaussian distribution.

Figure 1. Futures prices of the selected agricultural commodities
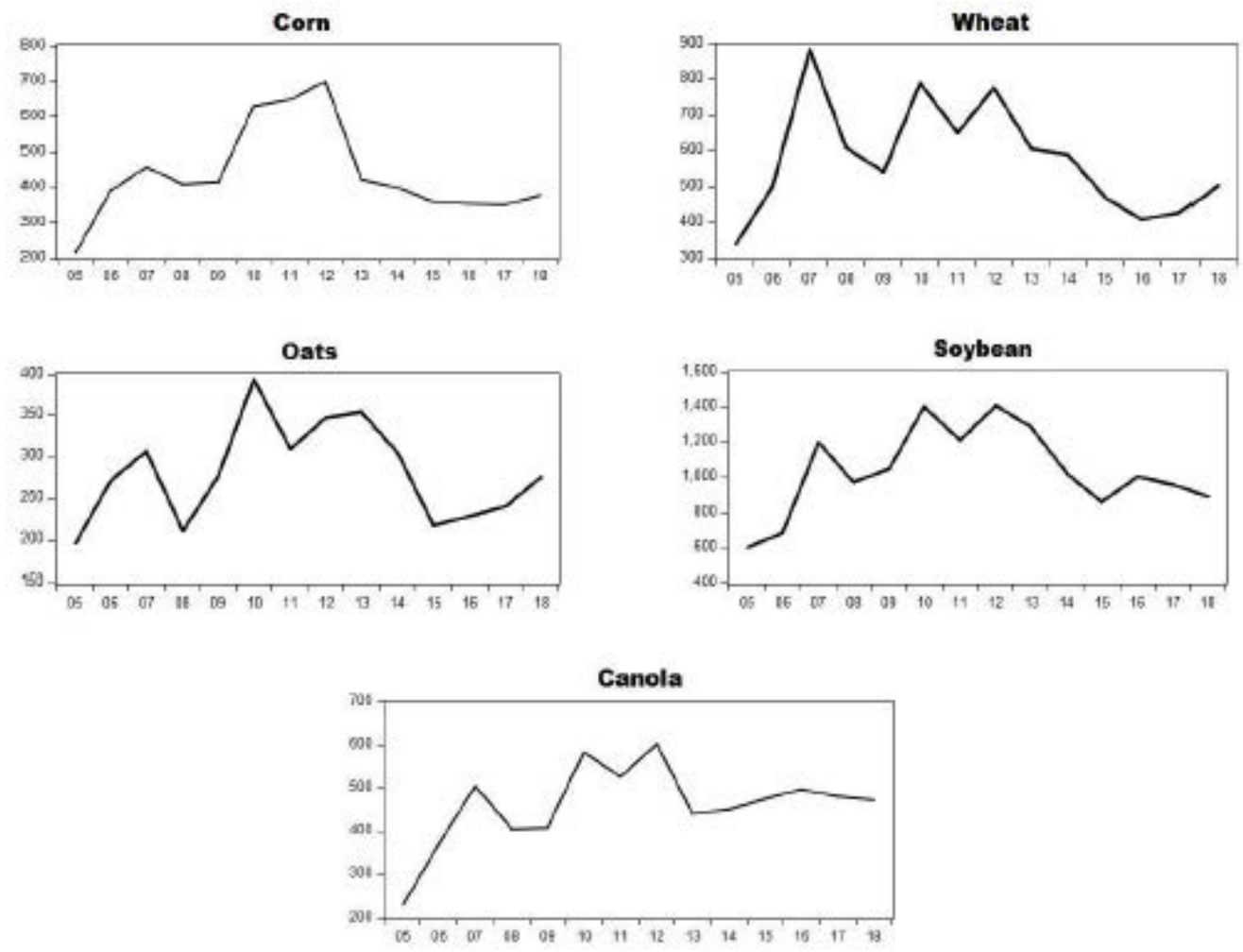

Source: Authors' calculation

As for the annual futures price changes, Table 1 reveals that the highest futures price changes have canola, whereas corn, soybean and wheat follow. Standard deviation speaks about unstable market conditions, and Table 1 suggests that wheat futures prices are the most unstable, while corn and oats follow. As in the cases of the annual production, all agricultural futures prices have relatively moderate skewness and kurtosis values, which implies normal distribution. Only soybean has relatively high skewness (0.917), meaning that soybean has the highest concentration of positive changes around the mean. But yet again, this value is sufficiently low to fit normal distribution. 
Figure 2. Annual production of the selected agricultural commodities in tons
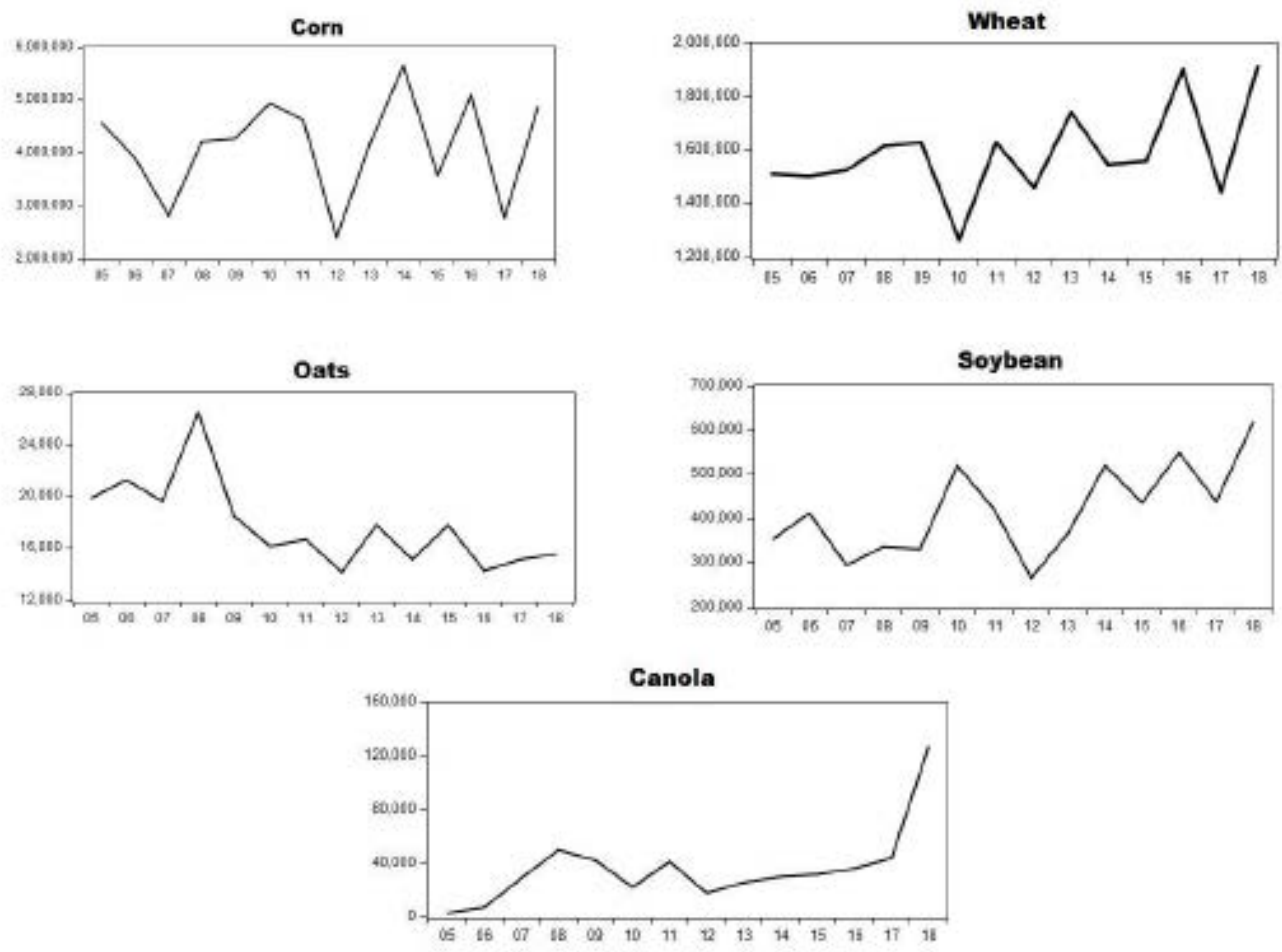

Source: Authors' calculation

Since this paper uses Bayesian quantile regression methodology, it is necessary to check the validity of the estimated Bayesian QR parameter. For that purpose, the paper relies on the visual inspection of the MCMC chains' convergence, which shows the evolution of the MCMC draws over the iterations. For our computational purposes, we use 3000 iterations. Figure 3 presents the trace-plots of the MCMC chain of the median quantiles, $\hat{\beta}(\tau)=0.5$, regarding the transmission effect from corn futures price changes to corn production changes. It is evident that trace-plot show a good performance, in terms that the effect of the initial values of the MCMC chains wears off very fast, while the MCMC sampler quickly moves to the stationary distribution. These findings undoubtedly confirm that the estimated median Bayesian quantile parameters are reliable. In order to preserve space and due to the fact that the trace-plots of all other commodities across all quantiles are very similar, we present in Figure 3 only traceplots for the corn case, whereas all other trace-plots can be obtained by request. 
Figure 3. Trace plots for the median quantile of corn

\section{Trace plot - corn}

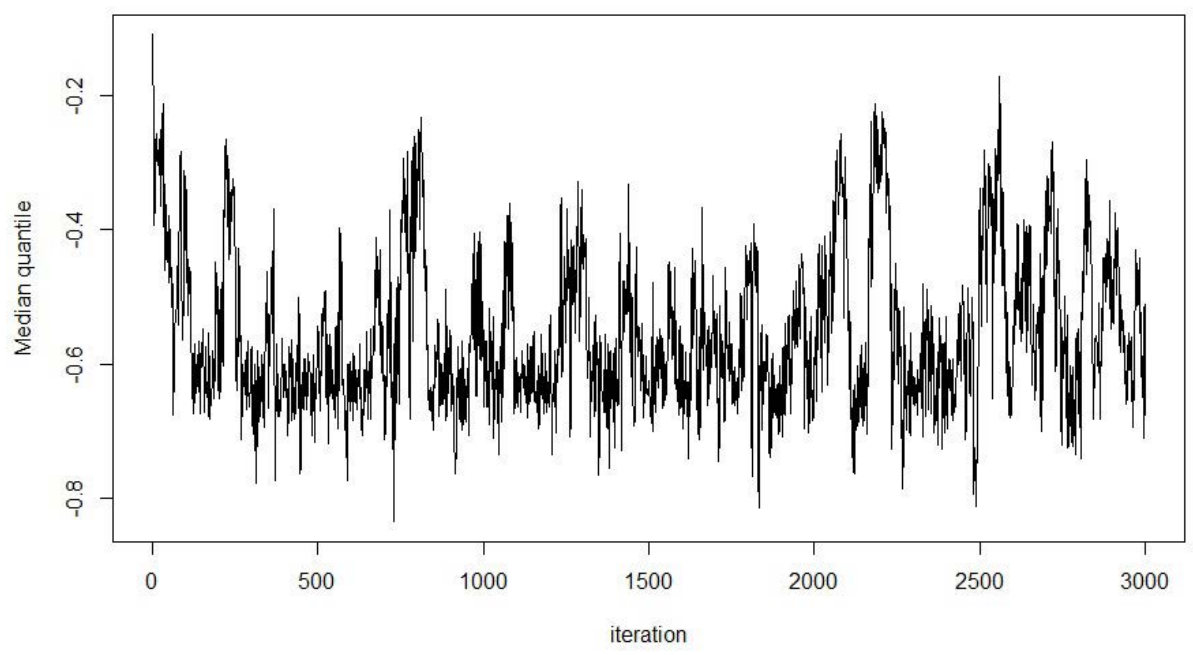

Source: Authors' calculation

\section{Research results}

This section presents and explains estimated Bayesian quantile parameters. In the process of Bayesian QR estimation, this paper considers five quantiles of the dependent variable distribution, i.e. $\tau=0.05, \tau=0.25, \tau=0.5, \tau=0.75$ and $\tau=0.95$. In other words, selecting these quantiles, we can grasp how futures price changes influence agricultural production in AP Vojvodina when this annual production was very low, low, moderate, high and very high, respectively. As have been said previously, the impact of futures price changes on agricultural production changes is assessed in two ways - contemporaneously and when futures price changes are observed from the previous period. Accordingly, contemporaneous effect is the first one to be examined, and Table 2 contains these estimated QR parameters. In addition, Figure 4 presents their graphical illustration. Table 2 shows that the majority of the estimated QR parameters bear negative sign, which means that increase in futures price changes negatively affect agricultural production of the selected plants in AP Vojvodina. These results have not logical foundation, and it means that current agricultural futures prices do not have influence on the agricultural production in AP Vojvodina, particularly for the cases of corn, wheat, oats and soybean. 
Table 2. Contemporaneous spillover effect from the futures price changes to the agricultural production changes

\begin{tabular}{|l|c|c|c|c|c|}
\hline & \multicolumn{5}{|c|}{ Quantiles } \\
\hline & 0.05 & 0.25 & 0.5 & 0.75 & 0.95 \\
\hline $\begin{array}{l}\text { Annual total } \\
\text { production }\end{array}$ & Very low & Low & Moderate & High & Very high \\
\hline Corn & -0.300 & 0.304 & -0.589 & -0.471 & -0.235 \\
\hline Wheat & -0.318 & -0.372 & -0.102 & -0.224 & 0.020 \\
\hline Oats & -0.458 & -0.577 & -0.430 & -0.422 & -0.331 \\
\hline Soybean & -0.741 & -0.229 & -0.531 & -0.233 & 0.168 \\
\hline Canola & -2.590 & -1.480 & -0.668 & 0.503 & 1.200 \\
\hline
\end{tabular}

Source: Authors' calculation

To be more precise, in the case of wheat, all QR parameters have negative sign, while the right-tail quantile is very close to zero. In the case of oats, all QR coefficients are negative, without exception. As for corn, all quantiles are negative, while only $\tau^{25}$ quantile is positive and relatively high (0.304), which means that it has economic significance. However, this is pretty much odd, because it implies that in years when corn production was low, a 100\% increase in current futures prices influences the rise in corn production by $30 \%$. Logically, it does not make much sense. Therefore, a viable explanation could be attributed to the fact that our sample covers relatively low number of observations, thus the estimated $\tau^{25}$ quantile is probably just an outlier. In order to confirm this suspicion, an additional estimation is conducted in the case of corn, but this time, the neighboring quantiles next to $\tau^{25}$ are estimated, i.e. $\tau^{15}$ and $\tau^{35}$. In this way, it could be confirmed/refuted whether $\tau^{25}$ quantile is only an exception. In the repeated estimation, $\tau^{15}$ quantile is -0.229 , whereas $\tau^{35}$ quantile amounts -0.338 , which means that $\tau^{25}$ quantile is only a random deviation. Therefore, it could be concluded in the case of corn that current futures price changes do not affect annual corn production, which is similar to the wheat and oats cases. In the case of soybean, only right-tail quantile is positive, while all others are negative. This means that in years when soybean production is very high, current futures prices affect current soybean production by $17 \%$, which is relatively low. 
Figure 4. Graphical illustration of the estimated quantile parameters, regarding the contemporaneous spillover
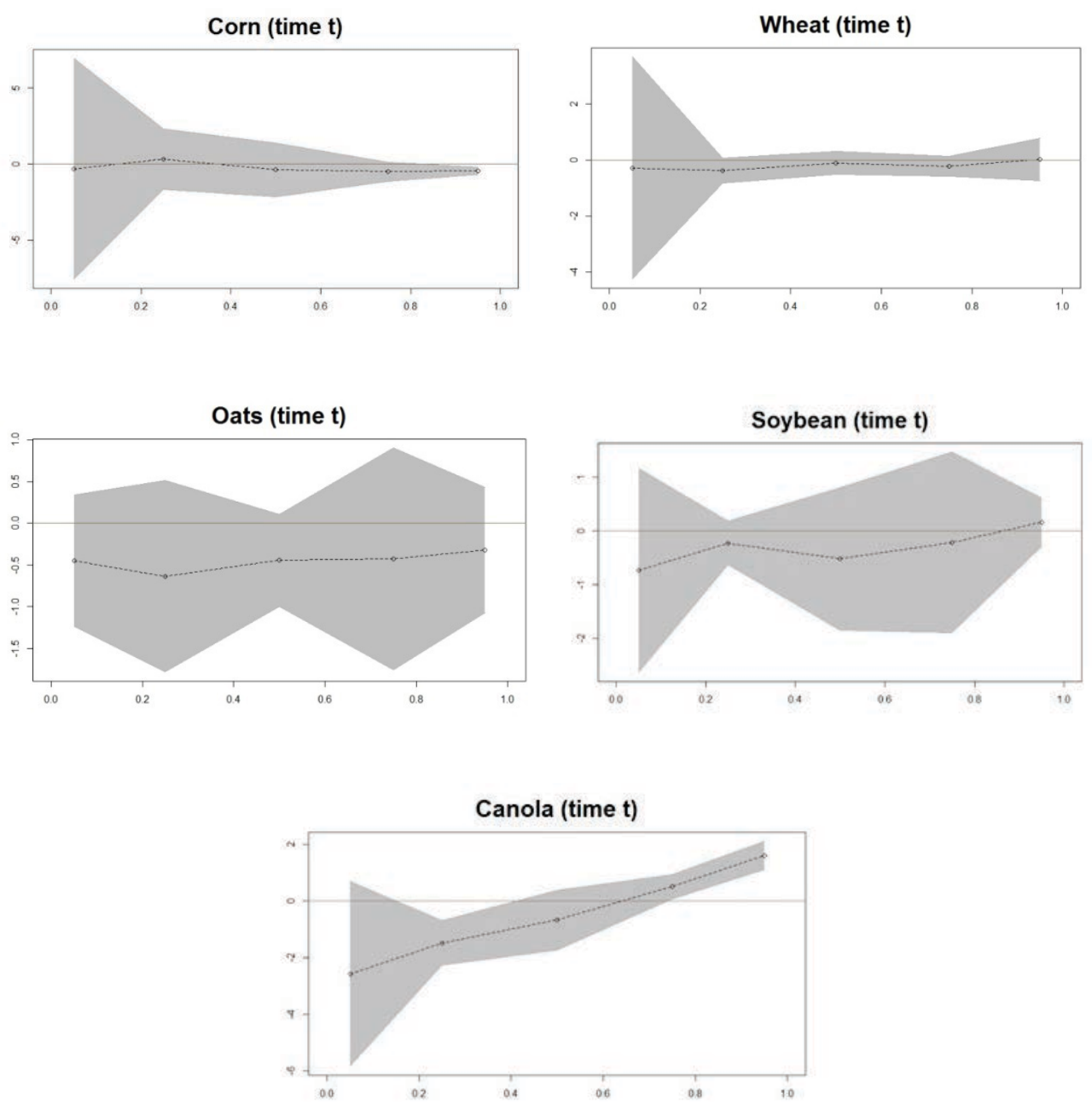

Note: The shaded area gives the adjusted credible intervals at 95 percent probability.

Source: Authors' calculation

On the other hand, in the case of canola, the results indicate that current futures prices have an effect on canola production in AP Vojvodina in the years when this production was high or very high. This assertion is based on estimated $\tau^{75}$ and $\tau^{95}$, which amounts 0.503 and 1.200 , respectively. This means that $100 \%$ increase in the canola prices exerts $50 \%$ and $120 \%$ rise in canola production in the years when canola production was high or very high, respectively. As have been said in the previous section, canola is an important feedstock used in a production of bio-diesel, and this could be the 
reason why global canola prices affect production of this plant in AP Vojvodina. This contention is in line with the paper of Baroi et al. (2014), who explained that biodiesel yet cannot compete with the diesel because of its higher production price. However, this cost can be reduced by using low quality and cheaper feedstocks such as used cooking oil, yellow grease, and green seed canola oil.

Besides estimation of contemporaneous effect, this paper also considers the transmission effect in the case when the futures prices from the previous year are took into account. This scenario, by all accounts, is more realistic than the previous one, and Table 3 reports these results. In addition, Figure 5 increases transparency by providing a visual inspection about the estimated $\mathrm{QR}$ parameters. Table 3 indicates that $\mathrm{QR}$ parameters are significantly different comparing to QR parameters in Table 2, which justifies consideration of both approaches. However, unlike results in Table 2, quantile parameters in Table 3 are mostly positive and relatively high across the quantiles. This means that global agricultural prices from the previous year present some kind of benchmark for Serbian farmers when it comes to their decision about the size of planted areas. In other words, in the case of corn, positive parameters are found at $\tau^{05}, \tau^{25}$ and $\tau^{50}$ quantiles, which is a strong indication that corn production in AP Vojvodina depends in a certain amount on the global corn prices, which is expected. On the other hand, in years when corn production is high or very high, estimated QR parameters are negative. At first glance, these results could look perplexing, but they actually enhance the credibility of the previous assertion. The rationale for these findings could be as follows. Production of corn is highly dependent on weather conditions. Consequently, it means that in those years when weather conditions were favorable for corn, production of this plant was high or very high, and these levels of production have nothing to do with the global corn prices, as $\tau^{75}$ and $\tau^{95}$ quantiles indicate. This explanation concurs very well with the assertion of Haile et al. (2017), who explained that weather extremes, such as shocks in both temperature and precipitation during crop growing months have serious consequences on the production and supply of agricultural commodities.

Table 3. Spillover effect from the previous year futures price changes to the current agricultural production changes

\begin{tabular}{|l|c|c|c|c|c|}
\hline & \multicolumn{5}{|c|}{ Quantiles } \\
\hline & 0.05 & 0.25 & 0.5 & 0.75 & 0.95 \\
\hline $\begin{array}{l}\text { Annual total } \\
\text { production }\end{array}$ & Very low & Low & Moderate & High & Very high \\
\hline Corn & 0.213 & 0.724 & 0.412 & -0.410 & -0.777 \\
\hline Wheat & -0.044 & 0.122 & 0.008 & 0.350 & 0.348 \\
\hline Oats & -0.267 & -0.150 & 0.359 & 0.460 & 0.189 \\
\hline Soybean & 0.783 & 0.454 & -0.269 & -0.257 & -0.317 \\
\hline Canola & 1.020 & 2.530 & 2.070 & 1.017 & -1.000 \\
\hline
\end{tabular}

Source: Authors' calculation. 
According to Table 3, the same explanation could be applied for soybean. Soybean is also a culture, which requires relatively high water-saturation levels of soil, implying that in those years when there were enough rainy days, soybean production was relatively high. In that regards, in years when soybean production was moderate, high or very high, rising soybean prices did not have influence on the levels of soybean production, as $\tau^{50}, \tau^{75}$ and $\tau^{95}$ quantiles suggest.

As for the case of wheat, four out of five quantile parameters are positive, only the first one is negative, while in the case of outs, three out of five QR parameters are positive, and the first two are negative. These cereals are not so water-demanding as corn and soybean are, thus QR parameters suggest that rising global prices of these agricultural commodities positively influence production of these cultures in the years when production of these cereals was relatively high. As a matter of fact, this influence for these two cereals ranges between $35-45 \%$, depending on the observed quantile.

Figure 5. Graphical illustration of the estimated quantile parameters, regarding the spillover effect from the previous year futures price changes to the current agricultural production changes
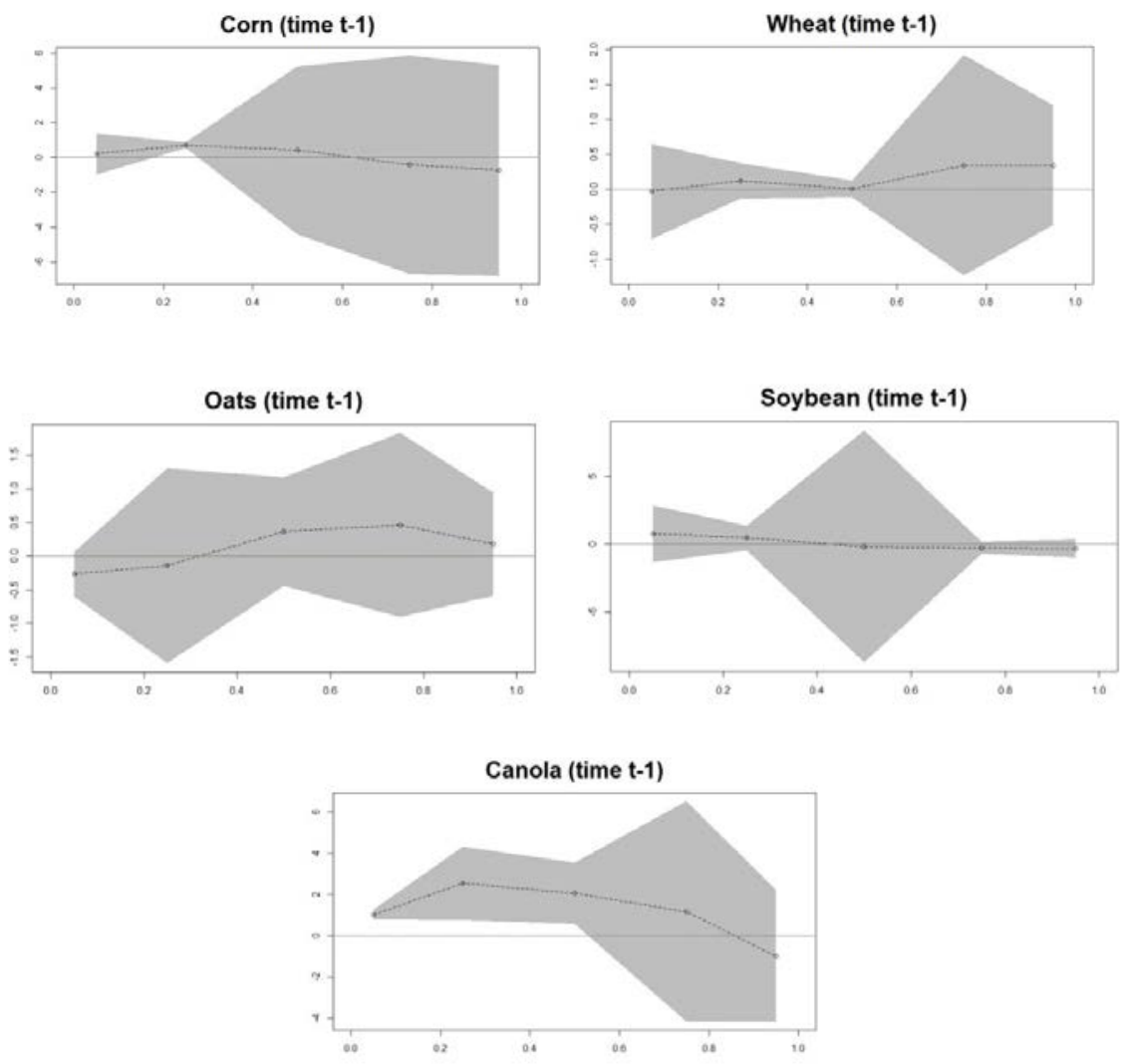

Note: The shaded area gives the adjusted credible intervals at 95 percent probability. Source: Authors' calculation. 
Table 3 indicates that positive QR parameters for canola are far the largest, comparing to all other QR parameters of all other plants. Their values range between $100-250 \%$, which strongly suggests that canola futures prices have an effect on production of this plant in AP Vojvodina. Comparing to Table 2, this effect is much higher. It is found that right-tail quantile parameter is negative, which means that in years when canola production was at its highest levels, global canola futures prices did not contribute to these production volumes. The explanation for this finding is similar as in the corn and soybean cases. Canola is big water consumer, and if rainy days are sufficient enough and well distributed during the vegetation season, canola yields could be significant. However, it does not mean that global futures prices have any effect on canola production in those very favorable years for canola. Bayesian QR parameters confirm this assertion very well. In addition, our findings are in line with the assertion of Pejanović and Gajdobranski (2012), who asserted that the production of oilseeds in Serbia is characterized by an upward trend, which is positive for price signals from the world market. Rising global demand for oilseeds, stemming from rising biofuel production and growing pre-oil demand, influences a higher price trend that will probably continue to grow in the future period.

\section{Conclusion}

This paper investigates whether global agricultural futures have any influence on the annual agricultural production in AP Vojvodina, which have never been done thus far. Five agricultural commodities are taken into account - corn, wheat, oats, soybean and canola. For the estimation purposes, the study uses robust Bayesian quantile regression, which can produce efficient quantile estimates even in low data setting. Besides, two scenarios are considered -1) current futures prices, and 2) futures prices from the previous year.

Estimated results clearly indicate that current futures prices do not affect current agricultural production of corn, wheat, oats and soybean in AP Vojvodina, since the estimated quantile parameters have negative sign or they are very small. These findings indicate that Serbian farmers do not take into account current futures prices when they make decisions how many hectares and of which culture they will plant. These results are in line with the expectations. On the other hand, when futures prices from the previous year are analyzed, the majority of estimated $\mathrm{QR}$ parameters bear positive sign, which means that Serbian farmers take into account in greater or lesser extent the global agricultural prices when they plan their annual agricultural plantation. According to the findings, canola futures have the greatest effect on the rising Serbian canola production, comparing to all other agricultural commodities. One of the reasons for such results could be the fact that canola is used as feedstock in an ever-growing production of bio-diesel. Thus, the hypothesis that has been set on the beginning of the researched has been confirmed.

The major novelty of this study is the usage of unconventional and very innovative Bayesian quantile regression, which can provide reliable QR parameters even when the research is limited with the availability of empirical data, which is the primary advantage of this approach. In addition, this study has shown that Serbian farmers are ready to take into account futures prices when they plant their annual agricultural plantation, which is very positive and somewhat unexpected conclusion. In other words, it gives us an indication that Serbian farmers are aware that they can protect themselves from 
the agricultural price changes on the world market simply by taking a long position on futures contracts. Of course, future studies will confirm or refute the results from this paper, using richer dataset and applying different methodology.

\section{Acknowledgements}

This research is result of the project funded by the Government of Autonomous Province of Vojvodina in 2019. The project number is 142-451-2406/2019-02/1.

\section{Conflict of interests}

The authors declare no conflict of interest.

\section{References}

1. Baroi, C., Mahto, S., Niu, C., Ajay K. Dalai, A.K. (2014) Biofuel production from green seed canola oil using zeolites. Applied Catalysis A: General, 469, 18-32., DOI: 10.1016/j.apcata.2013.09.034

2. Beckmann, J., Czudaj, R. (2014) Volatility transmission in agricultural futures markets. Economic Modelling, 36, 541-546., DOI: 10.1016/j.econmod.2013.09.036

3. Benoit, D.F., van den Poel, D. (2012). Binary quantile regression: a Bayesian approach based on the asymmetric Laplace distribution. Journal of Applied Econometrics, 27(7), 1174-1188., DOI: 10.1002/jae.1216

4. Benoit, D.F., van den Poel, D. (2017). bayesQR: A Bayesian Approach to Quantile Regression. Journal of Statistical Software, 76(7), 1-32., DOI: 10.18637/jss.v076.i07

5. Birovljev, J., Ercegovac, D., Radaković, M. (2012) Perspektive uvođenja robnih fjučersa na finansijsko tržište Srbije. Anali Ekonomskog fakulteta u Subotici, 27, 13-29. [in English: Birovljev, J., Ercegovac, D., Radaković, M. (2012) The perspectives of commodity futures introduction in Serbian financial markets. Anals of economic faculty in Subotica, 27, 13-29.]

6. Bohl, M.T., Siklos, P.L., Wellenreuther, C. (2018) Speculative activity and returns volatility of Chinese agricultural commodity futures. Journal of Asian Economics, 54, 69-91., DOI: 10.1016/j.asieco.2017.12.003

7. Bohl, M.T., Siklos, P.L., Stefan, M., Wellenreuther, C. (2019) Price discovery in agricultural commodity markets: Do speculators contribute? Journal of Commodity Markets, 100092., DOI: 10.1016/j.jcomm.2019.05.001

8. Dimpfl, T. Flad, M., Jung, R.C. (2017) Price discovery in agricultural commodity markets in the presence of futures speculation. Journal of Commodity Markets, 5, 50-62., DOI: 10.1016/j.jcomm.2017.01.002

9. Đurić, D., Ristić, J., Đurić, D., Vujanić, I. (2017) Export of agricultural and food products in the function of economic growth of republic of Serbia. Economics of Agriculture, 64(3), 887-900., DOI: 10.5937/ekopolj1703887d

10. Ignjatijević, S., Čavlin, M., Jahić, M. (2018) The impact of relevant factors on wheat supply and demand in the republic of Serbia. Economics of Agriculture, 65(1), 143-156., DOI: 10.5937/ekoPolj1801143I 
11. Jia, R-L., Wang, D-H., Tu, J-Q., Sai-Ping Li, S-P. (2016) Correlation between agricultural markets in dynamic perspective-Evidence from China and the US futures. Physica A: Statistical Mechanics and Its Applications markets, 464, 83-92., DOI: $10.1016 /$ j.physa.2016.07.048

12. Gilbert, C.L. (2010) How to understand high food prices. Journal of Agricultural Economics, 61(2), 398-425., DOI: 10.1111/j.1477-9552.2010.00248.x

13. Gulan, B. (2014) Stanje i perspektive poljoprivrede i sela u Srbiji, Privredna komora Srbije, Beograd. [in English: Gulan, B. (2014) Condition and perspectives of agriculture and village in Serbia. Economic chamber of Serbia, Belgrade.]

14. Haile, M. G., Wossen, T., Tesfaye, K., von Braun, J. (2017). Impact of climate change, weather extremes, and price risk on global food supply. Economics of Disasters and Climate Change, 1(1), 55-75., DOI: 10.1007/s41885-017-0005-2

15. Koenker, R., Bassett, G. (1978). Regression quantiles. Econometrica, 46(1), 3350., DOI: 10.2307/1913643

16. Kuzman, B., Ercegovac, D., Momčilović, M. (2018) Development of derivative trading on financial market and agribusiness sector in Serbia. Economics of Agriculture, 65(2), 601-616., DOI: 10.5937/ekopolj1802601k

17. Li, Z., Lu, X. (2012) Cross-correlations between agricultural commodity futures markets in the US and China. Physica A: Statistical Mechanics and Its Applications, 391(15), 3930-3941., DOI: 10.1016/j.physa.2012.02.029

18. Ma, F., Zhang, Y., Wahab, M. I. M., Lai, X. (in press) The role of jumps in the agricultural futures market on forecasting stock market volatility: New evidence. Journal of forecasting, DOI: 10.1002/for.2569

19. Maestri, V. (2013). Imputed rent and distributional effect of housing-related policies in Estonia, Italy and the United Kingdom. Baltic Journal of Economics, 13(2), 37-60., DOI: 10.1080/1406099x.2013.10840532

20. Mahbub, N., Gemechu, E., Zhang, H., Kumar, A. (2019) The life cycle greenhouse gas emission benefits from alternative uses of biofuel coproducts. Sustainable Energy Technologies and Assessments 34, 173-186., DOI: 10.1016/j.seta.2019.05.001

21. Marković, J., Prodanović, R., Mutibarić, J. (2013) Proizvodnja i promet pšenice u Srbiji. Ekonomika, 59(2), 92-100. [in English: Marković, J., Prodanović, R., Mutibarić, J. (2013). Production and trade of wheat in Serbia. Economica, 59(2), 92-100.]

22. Pejanović, R., Gajdobranski, A. (2012) Determinante proizvodnje uljarica u Evropskoj uniji i Vojvodini. Agroekonomika, 55, 64-85. [in English: Pejanović, R., Gajdobranski, A. (2012) Determinants of oilseed production in European union and Vojvodina. Agroeconomics, 55, 64-85.]

23. Sriram, K., Ramamoorthi, R.V., Ghosh, P. (2013). Posterior consistency of Bayesian quantile regression based on the misspecified asymmetric Laplace density. Bayesian Analysis, 8(2), 489-504., DOI: 10.1214/13-ba817

24. Živkov, D., Njegić J., Pećanac, M. (2014). Bidirectional linkage between inflation and inflation uncertainty - the case of Eastern European countries. Baltic Journal of Economics, 14(1-2), 124-139., DOI: 10.1080/1406099x.2014.993831 